\title{
Oral Cavity: A Forensic Kaleidoscope
}

\author{
Deepthi Darwin ${ }^{1}$ Soundarya Sakthivel ${ }^{1}$ Renita Lorina Castelino ${ }^{1}$ Gogineni Subhas Babu ${ }^{1}$ \\ Mohamed Faizal Asan ${ }^{1}$ Anand Shankar Sarkar ${ }^{1, \odot}$
} 1Department of Oral Medicine and Radiology, A.B. Shetty Memorial
Institute of Dental Sciences (ABSMIDS), Nitte (deemed to be
University), Mangalore, Karnataka, India
Address for correspondence Renita Lorina Castelino, MDS, A.B. Shetty Memorial Institute of Dental Sciences (ABSMIDS), Nitte (deemed to be University), Mangalore, Karnataka 575018, India (e-mail: renita.castelino@yahoo.com).
Abstract
Keywords
- forensic dentistry
- disaster victims
- inventions
- dental prosthesis
- three-dimensional printing

Forensic odontology is an integral part of the multidisciplinary field of forensic sciences that requires specialized training and perceptive knowledge for its application in full potential. Forensic odontology deals with the evidence pertaining to the oral and paraoral structures. Dentists are equipped with knowledge of orofacial structures and their variations prevailing among different ancestry. By implicating the history of dental treatments to the identification process, dentists extract unique and accurate information that aids in forensic identification. Crimes such as child abuse and domestic violence are often identified by the dentists during routine dental examinations and this can be used as an evidence to discern malefactors in such cases. This article provides a collective review of applications and methods in forensic odontology that helps legal authorities in the identification of individuals.

\section{Introduction}

Forensic odontology (or forensic dentistry) is defined as the branch of dentistry that addresses the proper handling and examination of dental evidence and the evaluation and presentation of dental findings in the interests of justice. Forensic odontology has become a fundamental part of large global forensic educational establishments such as American Academy of Forensic Sciences along with International Association of Identification. ${ }^{1}$ The identification of individuals in cases of mass disaster is complex due to severe disfigurement, charring, and decomposition. ${ }^{2}$ Antemortem and postmortem records are retrieved and correlation is done to set up an accurate identification. Most of these antemortem dental archives comprise of dental and medical histories, radiographs, written notes, study models, diagrams, clinical photographs, results of specific trials, prescriptions, charts, and referral letters. ${ }^{3}$ Dental identification can have applications such as comparative identification where postmortem dental records are compared with antemortem dental records to identify the person, to obtain identification of

published online Jun 14, 2021
DOI https://doi.org/ $10.1055 / \mathrm{s}-0041-1731117$ ISSN 2582-4287 person where antemortem records are not available, and to identify victims of mass catastrophes. ${ }^{4}$

Teeth are resistant to desiccation and decomposition and are one of the last tissues to disintegrate after death, attaining substantial significance in forensic investigations. ${ }^{5}$ Electronic record keeping has reduced the loss of data that is usually encountered with conventional methods. ${ }^{6}$ This review article intends to provide a general overview of the importance of forensic odontology with an emphasis on the different approaches for identification in a legal context.

\section{Discussion}

The analysis, handling, and presentation of dental evidences for legal matters are the main focus of forensic odontology. Single body recognition, disaster victim identification, estimation of age, and bite mark identification are the four primary aspects of forensic dentistry. ${ }^{7}$ The differentiating factor between the known distinctive features of missing individual (antemortem data) with that of retrieved findings from an unknown body (postmortem data) forms the basic 
groundwork of "identification" and diagnosis. ${ }^{6}$ Since the importance of forensic odontology in the field of judiciary is rapidly increasing, a thorough understanding of this field appears to be more than justified. The various techniques and methods applied in the field of forensic dentistry for identification of individuals are as follows.

\section{Ameloglyphics (Amelo: Enamel, Glyphics: Carvings)}

Automated software has been promoted for the reliable identification of the individuals, based on biometric based verification methodologies such as iris scanning, fingerprint verification, and recognition of facial features. Teeth are considered hard tissue analogs to fingerprints as both are unique to every individual. Enamel, the hardest tissue in humans, is known to show resistance to decomposition. The structural units of enamel are the enamel rods that form unique patterns. Millions of enamel rods can be seen in each tooth and their number varies from tooth to tooth. Longer enamel rods are found at the thicker portions, that is, cuspal area and shorter rods in the thinner portions, that is, cervical area. Ameloglyphics is the study of patterns of these enamel rods. Patterns of ends of the enamel rods found at the surface of tooth are known as tooth prints. ${ }^{5}$ Common methods to replicate these enamel rods are cellulose acetate paper, cellophane tape, and rubber base impression materials. Study of dental hard structures is made possible by means of peel that is a replica of $10 \%$ orthophosphoric acid etched mineral surface, that is, the enamel surface to study the enamel rod end pattern which is a unique pattern in all individuals. Peel is examined under a microscope with the incident or transmitted light. Modifications were done to study dental hard structures due to their unique mineralogical composition. ${ }^{2}$

A study by Christopher et al showed that these prints can be preserved for 4 to 5 months making them a consistent and valued tool for identifications in forensics. The study had its limitations as tooth prints may be unique to individuals only if the derived tooth prints were taken from a specific site from a particular tooth. Any mild changes either in the orientation or direction of the tooth prints can interfere while recording results in obtaining a new pattern from the same individual and from the same tooth site. ${ }^{5}$

\section{Dental Radiographs}

The dental radiographs are usually observed to compare findings between antemortem and postmortem radiographs including curvatures of roots, buried tips of roots, root canal treated teeth, and shapes of restoration with presence or absence of base underneath. Radiographs also reveal normal anatomy of tooth along with its anomalies, jaw bones, and sinus. Digitized dental radiographs can be superimposed to compare parameters such as spatial relationship of supporting structures of roots and teeth in antemortem and postmortem records. Such superimposed radiographs can be used for identification at certain stages of development of human dentition. ${ }^{3}$ In cases of antemortem records that are not accessible, the deceased's postmortem chart is used in excluding an individual's identity by comparing with the available antemortem archives of other individuals. ${ }^{8}$ Collection of postmortem-radiographic image is affected by factors such as the availability of appropriate dental X-ray apparatus, rigor mortis, aiming of X-ray beam toward the victim's body, and electrical supply in the working area. Age estimation techniques also utilize volumetric pulp tooth ratios extracted through three-dimensional (3D) reconstructions of cone-beam computed tomography images. ${ }^{9}$

\section{Estimation of Dental Age}

Demirjian et al furnished the developmental stages of teeth used in the assessment of chronological age. ${ }^{1}$ Johnson's method of estimation of age with a single tooth in adults is a modification of Gustafson's method involving several phases of deteriorating changes in the tooth such as attrition of the occlusal aspect, the loss of periodontal attachment, formation of secondary dentine in the coronal aspect, apposition of cementum, and resorption at apex and root transparency. Kvaal et al proposed an alternate technique of age estimation in adult patients through the measurement of pulp size from periapical radiographs of the tooth depending on the gender of an individual. ${ }^{1}$

\section{Bite Mark Evidence}

The identification and comparison of bite marks to the dental characteristics of the suspect are a contribution of dentistry to forensics. ${ }^{8,10}$ Bite marks can be observed in cases such as homicide, assault, and physical or sexual abuse. In addition, victims may also possess bite injuries from nonhuman sources. Generally, animal bites remain distinguished from injuries inflicted by human bites by differences seen in arch alignments and specific tooth morphology. Most animal bites cause shear injuries thus inflicting open wounds with lacerations of the skin distinguished by forensic odontologist by their different arch alignment and morphology of specific teeth. ${ }^{8}$

\section{Presentation of Bite Marks}

Bite marks can be recognized as a semicircular shaped injury that comprises two separate arcs, that is, one arc of the upper arch and the other of the lower. The central area of bite mark either has an absence of injury or may be seen with a diffuse bruise. Factors influencing the severity of a bite mark injury may include force of infliction of the original injury, the anatomical location bitten, and the time elapsed between infliction. ${ }^{10}$

\section{Collection of Bite Mark}

An influential item of evidence from a bite victim is photographs. Such photographs are to be taken at 90 degrees to the injury at a frequency of 24-hour interval regularly, with a camera on both the departed and the living victim to record its appearance. Subsequently, a thorough dental examination should be taken followed by a dental charting that clearly depicts the detailed presence and condition of 
each of the teeth, its modifications, and any restorations if undertaken. The next step is recording impressions of both the arches using the highly recommended impression material, poly-vinyl siloxane, combined with plastic stock trays. "Double swab" technique proposed by Sweet allows the maximum collection of DNA from the saliva deposited during the biting process. ${ }^{10}$ Bite mark seen on a nonhuman substrate such as perishable items should be photographed carefully, followed by swabbing and finally an impression must be taken thus allowing a "docking" analysis to be conducted followed by long term storage in a freezer.

The American Board of Forensic Odontology has provided a set of points to establish the injury status of a bite mark: (1) exclusion-the injury does not include a bite mark; (2) possible bite mark-biting cannot be ruled out as the injury shows a pattern that may be caused by teeth, but might also be caused by some other factors; (3) probable bite mark-pattern that strongly suggests or supports origin from teeth but could conceivably be caused by something else; (4) definite bite mark-pattern that confirms that teeth created the pattern of bite mark. ${ }^{10}$

\section{Tongue}

Analysis of the texture and shape of dorsal surface of tongue is significant as it reveals noteworthy morphological details proving its uniqueness as a tool in personal identification. Preservation of morphological aspects of the lingual surface of the tongue is achieved by the alginate molding technique for the duplication of minute subtleties exclusive for every individual. The lingual impression is recorded by means of neo colloid impression material that is applied steadily from the level of oral commissure to the tip of lingual aspect thus overcoming the regurgitation reflex. Obtained lingual impression along with the photographic image may establish a dependable method for forensic identifications. A relevant positive image is acquired with the resulting molds with type III dental stone. ${ }^{11}$ Biometric template of tongue consists of left and right lateral view and profile view. The normalized histogram with scale-invariant feature transform is used for analysis of tongue texture. Combination of templates of tongue algorithm and normalized histogram extraction techniques results in matching. ${ }^{12}$ For recording minute details and 3D analysis of tongue, alginate impressions followed by cast preparation is done, the alternation of which includes sublingual vein analysis. Placement of an ultrasound transducer in the sublingual area helps in assessing the function of the tongue. In case of tongue analysis, its histological examination can be utilized. ${ }^{11}$

\section{Palatal Rugae-Landmark for Forensic Diagnosis}

Palatal rugae are made up of connective tissue in the form of irregular ridges across the front portion of the palate and are often used as individual markers for biometric identification due to their unique features. Palatoscopy can be used in the necro identification in various mishaps of aeronautical origin to guarantee identity of pilots by means of antemortem records.
Following methods are commonly used to analyze the rugae patterns: (a) collection of photographic images and impressions of maxillary arch; (b) calcorrugoscopy that comprises the overlay print of palatal rugae in a maxillary cast to accomplish a comparative analysis; (c) computer-based software programs (e.g., RUGFP-ID); (d) stereophotogrammetry by a device called Traster Marker that permits accuracy; (e) stereoscopy through which 3D pictures of palatal rugae can be gained and is dependent on investigation of two unique pictures captured from two different focuses. ${ }^{12}$

Thomas and Van Wyk traced patterns of rugae from antemortem as well as postmortem dentures onto clear acetate for the purpose of superimposing such tracings onto the photographs of plaster models. ${ }^{13}$ Lately, Limson and Julian developed a PC software program based on the principle of fingerprint analysis. ${ }^{13}$ This program evaluates the points plotted on medial and the lateral extremities of all rugae and the obtained information is sequentially stored corresponding to the pixel position with an accuracy of $97 \%$ in a mock antemortem and postmortem comparison of rugae of the palate. Possible pattern changes of rugae may be under the influences of cleft palate surgery, forced eruption of canines, extraction of adjacent teeth, orthodontic movement, periodontal surgery, or finger sucking in childhood. ${ }^{13}$

A study conducted by De Angelis et al for identification purposes found that the normal growth of an individual does not change the characteristic features of his palatal rugae. ${ }^{14}$

\section{Lips}

Lips possess furrows and grooves. Santos classified lip grooves in 1967 as straight, curved, angled, and sinusoidal lines respectively. ${ }^{15}$ Cheiloscopy is a technique used in forensic odontology to identify individuals using lip tracing. Direct retrieval of lip prints is acquired from lips of the deceased and indirectly from inanimate objects. Lip print patterns should be traced within the first 24 hours of death, based on the position of mouth, to avoid any incorrect data arising from postmortem alterations of the lip of the deceased. Distinct grooves are seen in closed mouth position, whereas in open mouth position the grooves are poorly defined causing difficulty in interpretation. The various pathologies associated with lips such as mucocele, loss of anterior teeth resulting in loss of support, presence of fluid or debris on the lip surface, and postsurgical variations can result in alterations while recording lip prints.

\section{Various Methods to Record Lip Prints}

1. Use of a roller fingerprint.

2. Overlay tracings made of grooves on the surface of a non-porous mirror.

3. Photographing the suspect's lips.

Application of appropriate transferable medium to the lips such as lipsticks followed by pressing the individual's lips to cellophane tape or a piece of paper. Such prints can be processed with a conventional powder and developed with a magnetic powder and magna brush. 
Latent lip prints are developed via the magna brush method. The lip prints are pressed against the surface of a glossy, porous material or a smooth, nonporous material and allowed to solidify by subjecting them to a heat source. Tsuchihashi classified the pattern of lip prints into six types as follows: (I) complete straight grooves, (I') partial straight grooves, (II) branched grooves, (III) intersected grooves, (IV) reticular grooves, and (V) undifferentiated grooves. ${ }^{16} \mathrm{~A}$ preliminary study conducted by Furnari et al assessed the interrater dependability among various forensic odontologists who used Tsuchihashi classification and concluded that this classification failed to obtain a solid argument for reliability. ${ }^{16}$

\section{Restorations}

In cases of bodies burned beyond recognition, identification is possible by in-depth knowledge of charred dentition of the deceased and residues of restorative material if any. Teeth are categorized as intact (no damage), scorched (superficially parched and discolored), charred (reduction to carbon by means of incomplete combustion), and incinerated (burned to ash) when subjected to variable temperatures and time. ${ }^{17}$ Posterior teeth are often associated with restorations and acrylic dentures that can survive high temperatures. ${ }^{1}$ Parts of restored teeth discovered at the crime scene may be used to identify the victim or the suspect. Other scientific sources such as scanning electron microscopy (SEM) and energy dispersive X-ray spectroscopy (EDS), and microscopy are used to assist in recognition and differentiation of tooth related fragments. ${ }^{18} \mathrm{~A}$ study was conducted by Patidar et al to assess the degree of destruction in teeth structure, shape, and color, restoration and mandible after incineration process. The study concluded that with a rise in temperature, the decomposition rate of restorative material increases. The study also stated that resistance of the restoration to variable temperatures is unique with respect to the material itself and further added that there is deformation, loss of elasticity, carbonization, and fractures seen with respect to bones. ${ }^{17}$

\section{DNA}

The use of DNA technology gives answers to most of the ethical and legal problems that have to be addressed systematically ${ }^{19} \mathrm{~A}$ rich source of DNA is seen within the pulp cavity, coronal portion of pulp chamber, odontoblastic processes, radicular canals, and the cellular cementum. Since quality and not quantity of DNA is important, plenty of quality DNA is extracted from the root region. Cryogenic grinding is currently used to extract high-quality DNA material. ${ }^{20}$ Horizontal sectioning, vertical splitting, and normal endodontic access procedures are strategies introduced for separating DNA and its recovery from human teeth. DNA isolation is done by organic extraction method or silica-based DNA extraction methods. DNA can be amplified by polymerase chain reaction (PCR) and real-time PCR methods. ${ }^{19}$

\section{Implants-The Visual Aid}

Primary scientific identification of victims is possible using nonvisual methods such as fingerprint and DNA analysis with dental records. Loss of fingerprint particulars and denaturing of DNA may be present in cases where the victim has been burnt..$^{21,22}$ When an unidentified body with no available dental record is found with one or more implants in the jaws, evidences gathered from the type of implants used could aid in the investigation. ${ }^{3}$ Features of the recovered dental implants may contribute as the lone physical identifying data that is available because of their physical

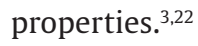

Compared with all other implants, only pure titanium implants showed color variation when subjected to a high temperature of $1125^{\circ} \mathrm{C}$. Any changes in the physical proportions due to the formation of an oxide layer should be contemplated before any metric investigation. ${ }^{23}$

\section{Crown}

Most of the dental crowns are made of porcelain material and the analysis of components of porcelain assists in identification. Fluorescent examination lamps have been used to examine the emitted fluorescence of porcelain crowns of murdered victims and compared with several control porcelain samples. Wave dispersion X-ray microanalyzer evaluates composition of porcelain crown and that of control sample to upsurge the neutrality of the results by means of quantitative analysis. $^{3}$

\section{Root Canal Filling Material}

The details of pre- and postincinerated elemental analysis of various endodontic filling materials can be used by the forensic odontologist for rapid reference. Bonavilla et al used SEM or EDS to evaluate the composition of the root canal obturating materials. This study highlighted that the elemental fingerprints of obturation materials, sealers, specific files, and cements can be utilized to assist in forensic identifications. ${ }^{24}$ The study by Bush et al revealed that big, classy laboratory-based SEM/EDS is typically not preferred over portable X-ray fluorescence spectrometer (XRF) because the various materials used in endodontics are readily and positively fingerprinted to perform the elementary examination of the deceased's postmortem remains. Ideally XRF spectroscopy suits for investigations that are performed in a contaminated or hazardous field setting. ${ }^{25}$

\section{Dentures and Denture Marking}

Millet and Jeannin in the year 2004 implanted a radio frequency identification transponder within a complete denture of upper arch. The system comprised of a transponder in addition to a handheld electronic reader. This affords to rapidly identify the deceased victims since metal restorations show outrageous resistance to every insults. ${ }^{26}$ The various methods used for denture marking are listed in - Table 1 . 
Table 1 Denture marking methods

\begin{tabular}{|l|l|}
\hline $\begin{array}{l}\text { Surface marking } \\
\text { methods }\end{array}$ & $\begin{array}{l}\text { Inclusion methods (for complete } \\
\text { dentures) }\end{array}$ \\
\hline Engraving method & Clear acrylic T bar method \\
\hline Fiber tip pen method & Bar coding method \\
\hline $\begin{array}{l}\text { Wecker's electro pen } \\
\text { method }\end{array}$ & Radio frequency identification tag \\
\hline $\begin{array}{l}\text { Onion skin paper } \\
\text { method }\end{array}$ & $\begin{array}{l}\text { Metallic band according to Swedish } \\
\text { guidelines }\end{array}$ \\
\hline $\begin{array}{l}\text { Denture bar coding } \\
\text { method }\end{array}$ & Microlabeling \\
\hline Stevenson's method & Memory card method \\
\hline Laser etching method & Data matrix code \\
\hline
\end{tabular}

The trained professionals usually incorporate the complete details of the patients in the dentures by means of denture marking. The disadvantage of such systems is that the retrieved data from these systems require distinct equipment to read and interpret the data such as memory card, radio frequency identification, and barcodes as these cannot be hurriedly obtained in crises such as mass disasters and road accidents. With altered opinions from the worldwide communal of forensic odontologists, encouragement for the adoption of a universal plan intending to denture marking and collaboration is essential. ${ }^{27}$

\section{Oral Jewelry and Piercings}

Oral piercings and tattoos are increasingly used by youngsters as a fashion statement. Any form of jewelry that would be left after a mass disaster or an air crash is essentially used for the purpose of human identification. The various oral jewelry commonly noted are listed in -Table 2. As stated by American Academy of Pediatric Dentistry, oral jewelry leads to amplified levels of plaque, caries, recession with or without gingival inflammation, periodontal disease that may be localized to the area of piercing. The other problems associated with oral piercing are reduced articulation, infection with pain, tooth fractures, allergy to the metals used, metal hypersensitivity reactions, formation of scar, speech impediment, Ludwig's angina, and associated nerve damage. Pigmented iatrogenic lesion such as "amalgam tattoo" and exogenic lesion such as "graphite tattoo" are also not uncommon among people. ${ }^{28}$

\section{Physical Abuse}

Physical abuse usually presents as bruising, abrasion, laceration, hematoma, or ecchymosis. In the orofacial region, it may be seen in the palate, gingiva, or dentition. Lacerations in the labial or lingual frenum are hallmark signs of physical abuse in minors. They may be a result of forced feeding or any other aggressive activity. Teeth fracture, avulsions, dislocations may be seen secondary to trauma. Discolored teeth may be seen in cases where the teeth have become nonvital due to previous trauma. Maxillary and mandibular bone fractures may also be seen in severe forms of physical abuse. The
Table 2 Various oral jewelry noted in the oral cavity

\begin{tabular}{|l|l|}
\hline Design & Forensic Value \\
\hline Tooth jewel & $\begin{array}{l}\text { Resins are used in dentistry to attach } \\
\text { microjewels on the facial surface of teeth as } \\
\text { these have resistance toward high temper- } \\
\text { atures and water environmental conditions }\end{array}$ \\
\hline $\begin{array}{l}\text { Hallmarked } \\
\text { implant }\end{array}$ & $\begin{array}{l}\text { Ceramics or various metal implants have } \\
\text { desirable characteristics features such as } \\
\text { resistance to corrosion and temperature } \\
\text { similar to stainless steel }\end{array}$ \\
\hline $\begin{array}{l}\text { Hallmarked pin/ } \\
\text { post }\end{array}$ & $\begin{array}{l}\text { Seen within the tooth structure it has } \\
\text { resistance to both water and heat and } \\
\text { these pins are hallmarked the same way as } \\
\text { the implants }\end{array}$ \\
\hline $\begin{array}{l}\text { Tooth or crown } \\
\text { with tattoo }\end{array}$ & $\begin{array}{l}\text { Has resistance to both temperature and } \\
\text { water as these are minute jewels placed on } \\
\text { ceramics }\end{array}$ \\
\hline $\begin{array}{l}\text { Removable tooth } \\
\text { ring }\end{array}$ & $\begin{array}{l}\text { Ceramics, stainless, or sterling steel are } \\
\text { made used in the removable form because } \\
\text { of its heat and corrosion resistance } \\
\text { properties }\end{array}$ \\
\hline Fixed tooth ring & $\begin{array}{l}\text { Ceramics, stainless, or sterling steel are } \\
\text { placed on the anatomical crown. These } \\
\text { are used because of the protective nature } \\
\text { of oral cavity and because of its heat and } \\
\text { corrosion resistance properties }\end{array}$ \\
\hline
\end{tabular}

paraoral structures should also be examined for suspected injuries. Periorbital hematoma, contusions, ptosis, dislocated lens, retinal or subconjunctival hemorrhage, nasal fracture, rupture of the tympanic membrane, and auricular hematomas are other commonly noted signs of physical abuse in the orofacial region. ${ }^{7}$

\section{Sexual Abuse}

Erythema, ulcer, or lacerations are seen on the lips, tongue, and palate in cases of sexually abused victims. Bite marks are also common findings in sexually abused victims. ${ }^{7}$ In case of forced oral sex, petechiae may be noted at the junction of hard and soft palate or on the floor of the mouth. In case of a violent blow to the upper lip, a tear of the superior labial frenum is a pathognomonic sign of abuse in nonambulatory children. ${ }^{29}$

Vesicles with purulent discharge or ulcers and condylomatous lesions of nose, lip, tongue, palate, or pharynx may be seen in cases of infections caused due to sexually transmitted diseases (STD). In suspected cases of STD, comprehensive examination and laboratory culture for syphilis, gonorrhea, human immunodeficiency virus, chlamydia, and human papillomavirus are recommended in accordance with the "guidelines for the evaluation of sexual abuse of children" (American Academy of Pediatrics). ${ }^{7}$

\section{Dental Neglect}

Dental neglect as defined by the American Academy of Pediatrics Dentistry is "willful failure of parent or guardian to seek and follow the treatment necessary to ensure a level of oral health essential for adequate function and 
freedom from pain and infection." Easily identifiable oral and paraoral signs of neglect include early childhood caries, improper oral hygiene, halitosis, untreated rapidly progressive dental caries, abscess, periodontal disease, recurrent odontogenic infections, aphthous lesions that occur as a consequence of a deficient nutritional status. Dentists can carry out an early diagnosis of dental neglect from the parent as an absent or uncertain anamnestic to concrete questions regarding child's physical and psychological growth stages. $^{7}$

\section{Three-Dimensional Printing-An Aid to Forensics}

The invention rapid prototyping, popularly referred to as 3D printing, includes both prototyping and manufacturing process in every field including medicine and dentistry. Reconstruction of face, identification and reconstruction of weaponries used, and identification of fracture pattern are some of the innumerable applications of 3D printing. 3D printing is positively employed to unravel several unsolved cold cases. Recreation of major bones including the skull is made possible with the postmortem scans of victims and the reconstruction of such detailed anatomic structures noninvasively is one among the major advantages of 3D printing that is utilized primarily to solve cases. ${ }^{30}$

\section{Conclusion}

The process of recognizing a large number of victims of natural disasters and detection for the prosecution of criminal activity is complicated. For this purpose, forensic profession employs science and technology to ensure delivery of justice, necessitating the coordinated efforts of a multidisciplinary team that covers all dental specialties. An unwavering effort must be made for the uptake of international guidelines and codes to computerize all data using readily available technologies.

\section{Conflicts of Interest}

None declared.

\section{References}

1 Krishan K, Kanchan T, Garg AK. Dental evidence in forensic identification - an overview, methodology and present status. Open Dent J 2015;9:250-256

2 Sha SK, Rao BV, Rao MS, Kumari KVH, Chinna SK, Sahu D. Are tooth prints a hard tissue equivalence of finger print in mass disaster: a rationalized review. J Pharm Bioallied Sci 2017;9(Suppl 1) :S29-S33

3 Chugh A, Narwal A. Oral mark in the application of an individual identification: From ashes to truth. J Forensic Dent Sci 2017;9(2):51-55

4 Ata-Ali J, Ata-Ali F. Forensic dentistry in human identification: a review of the literature. J Clin Exp Dent 2014;6(2):e162-e167

5 Christopher V, Murthy S, Ashwinirani SR, Prasad K, Girish S, Vinit SP. Can dead man tooth do tell tales? Tooth prints in forensic identification. J Forensic Dent Sci 2017;9(1):47

6 Manica S, Forgie AH. Forensic dentistry now and in the future. Dent Update 2017;44(6):522-530
7 Costacurta M, Benavoli D, Arcudi G, Docimo R. Oral and dental signs of child abuse and neglect. Oral Implantol (Rome) 2016;8(2-3):68-73

8 Marsden P. The forensic odontologist: roles and responsibilities. Dental Nursing 2010;6(12):710-713

9 De Valck E. Protocols for dental AM data management in disaster victim identification. J Forensic Sci Criminal Inves 2017;4(4):1-9

10 Pretty IA. Forensic dentistry: 2. Bitemarks and bite injuries. Dent Update 2008;35(1):48-50, 53-54, 57-58 passim

11 Johnson A, Gandhi B, Joseph SE. A morphological study of tongue and its role in forensics odontology. J Forensic Sci \& Criminal Inves 2018;7(5):1-5

12 Jeddy N, Ravi S, Radhika T. Current trends in forensic odontology. J Forensic Dent Sci 2017;9(3):115-119

13 Jain A, Chowdhary R. Palatal rugae and their role in forensic odontology. J Investig Clin Dent 2014;5(3):171-178

14 De Angelis D, Riboli F, Gibelli D, Cappella A, Cattaneo C. Palatal rugae as an individualising marker: reliability for forensic odontology and personal identification. Sci Justice 2012;52(3):181-184

15 Divakar KP. Forensic odontology: the new dimension in dental analysis. Int J Biomed Sci 2017;13(1):1-5

16 Dineshshankar J, Ganapathi N, Yoithapprabhunath TR, Maheswaran T, Kumar MS, Aravindhan R. Lip prints: role in forensic odontology. J Pharm Bioallied Sci 2013;5(Suppl 1) :S95-S97

17 Patidar KA, Parwani R, Wanjari S. Effects of high temperature on different restorations in forensic identification: dental samples and mandible. J Forensic Dent Sci 2010;2(1):37-43

18 Hinchliffe J. Forensic odontology, Part 1. Dental identification. Br Dent J 2011;210(5):219-224

19 Manjunath BC, Chandrashekar BR, Mahesh M. Vatchala Rani RM. DNA profiling and forensic dentistry-a review of the recent concepts and trends. J Forensic Leg Med 2011;18(5):191-197

20 Shamim T. Deoxyribonucleic acid profiling in forensic dental identification. Indian J Hum Genet 2013;19(4):513

21 Lake AW, James H, Berketa JW. Disaster victim identification: quality management from an odontology perspective. Forensic Sci Med Pathol 2012;8(2):157-163

22 Mishra SK, Mahajan H, Sakorikar R, Jain A. Role of prosthodontist in forensic odontology. A literature review. J Forensic Dent Sci 2014;6(3):154-159

23 Berketa J, James H, Marino V. Dental implant changes following incineration. Forensic Sci Int 2011;207(1-3):50-54

24 Bonavilla JD, Bush MA, Bush PJ, Pantera EA. Identification of incinerated root canal filling materials after exposure to high heat incineration. J Forensic Sci 2008;53(2):412-418

25 Bush MA, Miller RG, Prutsman-Pfeiffer J, Bush PJ. Identification through X-ray fluorescence analysis of dental restorative resin materials: a comprehensive study of noncremated, cremated, and processed-cremated individuals. J Forensic Sci 2007;52(1):157-165

26 Millet C, Jeannin C. Incorporation of microchips to facilitate denture identification by radio frequency tagging. J Prosthet Dent 2004;92(6):588-590

27 Kareker N, Aras M, Chitre V. A review on denture marking systems: a mark in forensic dentistry. J Indian Prosthodont Soc 2014; 14(Suppl 1) :4-13

28 Farrukh F, Mânica S. Fashion for a reason: oral jewellery to aid forensic odontology. J Forensic Leg Med 2019;66:38-43

29 Lin HW, Wieland AM, Ostrower ST. Child abuse presenting as oral cavity bruising. Otolaryngol Head Neck Surg 2009;141(2):290-291

30 Khanna S, Dhaimade P. Exploring the 3rd dimension: application of 3D printing in forensic odontology. J Forensic Sci Crim Investig 2017;3(3):1-3 